\title{
Necessary alternatives: patients' views of asthma treatment
}

\author{
This article was published in the following Dove Press journal: \\ Patient Preference and Adherence \\ 19 June 2010 \\ Number of times this article has been viewed
}

\section{Helen Kopnina' \\ Joke Haafkens ${ }^{2}$}

'Amsterdam Institute for Advanced Labor Studies, University of Amsterdam; ${ }^{2}$ Department of General Practice, Academic Medical Centre of the University of Amsterdam, The Netherlands
Correspondence: Helen Kopnina Amsterdam Institute for Advanced Labor Studies, University of Amsterdam, Plantage Muidergracht 12, 1018TV Amsterdam, The Netherlands Tel +I I 3I 205254346 Email h.kopnina@uva.nl
Abstract: This article is based on semistructured interviews and focus groups conducted with 27 asthma patients in The Netherlands who chose complementary and alternative medicine (CAM) for treatment of their condition. All subjects were contacted through an online forum for asthma patients hosted by the Dutch Asthma Foundation. Nineteen subjects (12 women and seven men) between the ages of 29 and 65 years participated in the interviews, held between June 2009 and January 2010. All of the participating subjects had experience with conventional medications, including anti-inflammatory corticosteroids and bronchodilators. For the focus group meeting, held in February 2010, the sample included seven subjects (four women and three men) between the ages of 31 and 46 years, none of whom had ever used conventional medication and all of whom were using CAM. All subjects in the sample had been diagnosed with asthma by their physician or lung specialist. The study examined the causes of patient noncompliance with the prescribed medical regime. It is argued that evidence-based rationality on the part of subjects is an overlooked dimension of their experience of asthma. This study demonstrates the role that the patients' social network, including medical practitioners, friends, and family, and other asthmatics, plays in the process of decision-making and choices about treating asthma. It also demonstrates the role of patients' information-searching strategies. The author concludes that patient noncompliance with commonly prescribed medication and selection of alternative medical treatment is less a matter of denial of their diagnosis or the severity of their illness, but more a matter of choice informed by evidence-based rationality.

Keywords: asthma, complementary alternative and medicine (CAM), evidence-based medicine (EBM), patient non-compliance, decision-making, indentity

\section{Introduction}

One of the most significant features of the prevailing Western medical paradigm is its growing reliance on scientific evidence. The movement towards evidence-based medicine (EBM) was a response to concerns about variations in quality of care, the rapid growth of medical technology, the patient empowerment movement, and psychologic research that raised questions about the quality of human judgment and decision-making. ${ }^{1}$ The central tenet of EBM is that, when making decisions about the care of patients, physicians should integrate their individual clinical expertise with the best available evidence from systematic research. EBM categorizes different types of clinical evidence and ranks them according to strength of proof. The strongest evidence for therapeutic interventions is provided by a systematic review of randomized, double-blind, placebo-controlled trials involving a homogeneous patient population with a specific disorder. ${ }^{2}$ In contrast, patient testimonials, case reports, and even expert 
opinion, have little value because of the placebo effect, the biases inherent in observation and reporting of cases, and the difficulties in ascertaining who is an expert. ${ }^{3}$

Current clinical guidelines have the aim of guiding and standardizing medical decision-making regarding diagnosis, management, and treatment in specific areas of health care. Such documents have been in use throughout the history of medicine. However, in contrast with previous approaches, which were often based on tradition or authority, modern medical guidelines are typically based on the paradigm of EBM.

Advocates of EBM have welcomed the stronger scientific foundation of clinical guidelines, while critics fear that they will lead to "cookbook medicine", with the clinician as sole decision-maker. ${ }^{4}$ This fear has been echoed by David Sackett, the founder of the Oxford Centre for Evidence-based Medicine. In a series of articles, he pointed out that the concept of EBM was being widely misinterpreted through an almost exclusive reliance on evidence from randomized clinical trials for the determination of treatment and care regimens, and the abandonment of the collaborative practice of knowledge sharing between doctors and patients. ${ }^{5}$

Over the past 40 years, there has been a sharp increase in the global prevalence of asthma, particularly in children, as well as in the morbidity, mortality, and economic burden associated with the disease. ${ }^{6}$ Currently, there are approximately 300 million people worldwide who have asthma. ${ }^{7}$ The treatment of asthma has been an early target for standardization via clinical guidelines. ${ }^{4}$ As some of the older tenets of asthma treatment were revised, ${ }^{8}$ easily identifiable "wrong" old practice still existed side by side with better, "updated" expert practice. Guidelines were seen as an instrument for keeping physicians updated and guiding them towards better, evidence-based practice. After publishing a first set of clinical guidelines for the diagnosis and management of asthma 1997, the National Heart, Lung, and Blood Institute of the US National Institutes of Health issued updated guidelines in 2002 and 2007. However, the overall effect of clinical guidelines for asthma is mixed and disappointing, considering the stakes in terms of both health and spending. Internationally, asthma treatment continues to be characterized by "unacceptable" treatment variation, despite the availability of guidelines. ${ }^{9} 10$

Current guidelines contain no clear direction for the use of CAM therapies for asthma, but an increasing number of patients are nevertheless opting for this treatment. ${ }^{11}$ The driving question behind this study is why some asthma patients choose noncompliance with recommended conventional Western medicine and turn instead to CAM therapies.

\section{What is known about CAM and asthma alternatives?}

EBM relies mainly on evidence gathered from systematic reviews of randomized controlled trials. Although the number of randomized controlled trials on CAM has increased in recent decades ${ }^{12}$ the Cochrane Library indexes only one review examining the effect of CAM in the management of asthma. ${ }^{11}$ Only two of the 15 reviewed studies showed a positive effect of CAM on asthma outcomes. The review's most important conclusion is that " ... more research is needed to assist in determining the efficacy of CAM therapies in asthma management".

Nevertheless, in many Asian and Western cultures, herbal therapies are commonly used for asthma. Despite an improved understanding of the pathophysiology of asthma, well established standards of practice, advanced therapies, and available pharmaceuticals, parents of asthmatic children may augment their child's conventional asthma medication with various CAM therapies. ${ }^{13,14}$ CAM use is indeed widespread among children, because their parents are seeking a cure for asthma, as well as alternative methods that are natural and without long-term side effects. ${ }^{15-17}$

Traditional Chinese medicine (TCM), used in Asia for centuries, has come to play a role as a CAM modality in Western health care. There is increasing scientific evidence supporting the use of TCM for asthma treatment. A review article by $\mathrm{Li}$ and Brown ${ }^{18}$ discusses promising TCM interventions for asthma and explores their possible mechanisms of action. The authors reviewed five clinical studies of antiasthma TCM herbal remedies and on the basis of the data in the publications, summarized possible mechanisms underlying their effects, such as anti-inflammatory properties, inhibition of airway smooth muscle contraction, and immunomodulation. The authors concluded that evidence from clinical studies supports the beneficial effects of TCM herbal therapy in asthma. A number of mechanisms may be responsible for the efficacy of these agents, and these need to be addressed in future research. ${ }^{18}$

$\mathrm{Li}$ and Brown ${ }^{18}$ identified three clinical studies involving children using traditional Chinese antiasthma medications. These included several preparations, including modified mai men dong tang (mMMDT, consisting of five herbs), ding chuan tang (nine herbs), and STA-1, consisting of a combination of mMMDT and lui wei di huang. In all three studies, the subjects continued their prescribed conventional medical regimen, but the treatment group was given a TCM formula and the control group was given a placebo. The treatment group demonstrated an improved forced expiratory volume 
compared with controls in all three studies. All participants were able to tolerate the TCM formulas well. In another study utilizing the principles of TCM, sanfujiu (a paste consisting of five Chinese herbs) was applied to treat allergies and asthma by increasing yang qi ("nature of the sun" heat) in the lungs. ${ }^{17}$ This study included 119 subjects of all ages. Those with asthma were more likely to report that the sanfujiu treatment was effective than subjects who had other allergic diseases.

Stockert et $\mathrm{al}^{19}$ examined the effectiveness of a combination of laser acupuncture and probiotics in the treatment of asthma. A small group of 17 children participated in a randomized, placebo-controlled, double-blind study of TCM in asthmatic children. Laser acupuncture was substituted for needle acupuncture, and probiotics derived from nonpathogenic Enterococcus faecalis were administered in place of the TCM herb, jin zhi. The control group was treated with a laser pen and given placebo drops to ingest. The results of this study demonstrated that the treatment group had significantly decreased bronchial hyperreactivity, as indicated by decreased weekly peak flow variability. ${ }^{19}$ In addition, a recent study by Wei and Gong ${ }^{20}$ shows that acupuncture can also have a remarkable effect in stopping an acute asthma attack.

Arnold et $\mathrm{al}^{21}$ have reviewed studies of the efficacy and safety of herb- and plant-based preparations for the treatment of asthma. The authors concluded that the evidence base for the effects of herbal treatments is hampered by the variety of treatments assessed, poor reporting of results, and a lack of available data. However, according to the investigators, some findings from the reviewed studies were positive and warrant additional, well-designed trials.

An important part of the assessment of CAM modalities is the therapeutic-toxicologic safety profile (risk-benefit ratio), and further research evaluating the clinical efficacy and mechanism of action of various CAM interventions for asthma is greatly needed. ${ }^{22} \mathrm{Li}$ and Brown ${ }^{18}$ and Mainardi et $\mathrm{al}^{23}$ have summarized the difficulties of testing biologically-based TCM modalities, pointing out that isolation and identification of active constituents may be difficult because of the nature of the herbs and of manufacturing and preparation processes; the synergistic effect of herbal combinations complicates the ability to determine the exact effect; TCM formulas are traditionally created for the individual, and standardization of TCM may not be effective; random, blinded studies are difficult to conduct when the subject's perception of CAM therapies may influence the results; and there is a need for more controlled clinical trials to test the efficacy of TCM formulas. ${ }^{18,23}$ An additional hypothesis to explain the lack of conclusive evidence of the efficacy and safety of CAM is that the type of funding may have biased the design of studies and interpretation of findings. ${ }^{24}$ Funding by the pharmaceutical industry is associated with design features that are less likely to lead to the discovery of statistically significant adverse effects of conventional drugs, such as inhaled corticosteroids, and to more favorable clinical interpretations of such findings. It has also been recommended that disclosure of conflicts of interest should be mandatory for a more balanced opinion in the reporting of drug safety studies. ${ }^{25}$

\section{Patient noncompliance}

The issue of compliance with prescribed medication regimens has traditionally been dominated by the perspective of the health professional. Increasingly, however, medical anthropologists and sociologists have started to present the patient's point of view.

Evans and Spelman ${ }^{26}$ argue that the patient's level of compliance is influenced by psychologic factors, such as anxiety, motivation to recover, attitude towards the illness, the drug and the doctor, as well as the attitudes and beliefs of significant others. The authors conclude that, contrary to widespread medical belief, the evidence do not support the view that medication noncompliance is a deviant form of behavior influenced by patient characteristics.

Mühlhauser and Lenz's study ${ }^{27}$ of noncompliance suggests that it is rarely provoked intentionally or by laziness, concluding that patients should not be the first to be blamed for lack of therapeutic success. Noncompliance on the part of health care providers when supplying patients with necessary information and skills is also an important cause of poor treatment outcomes. Patient knowledge, when evidence-based and relevant to the patient, can enable patients to assume an important part in their disease management. This can improve health outcomes, although it may lead to intelligent noncompliance and a worsening of treatment outcomes according to conventional assessment criteria.

Some studies have linked patients' treatment decisions to their identity. In their study of asthmatics, Adams et $\mathrm{al}^{28}$ argue that asthma patients' noncompliance with (Western) medical regimens is a matter of patient denial of their identity as an asthmatic. Beatty and Joffe ${ }^{29}$ argue that chronic illness can cause a dramatic shift in an individual's identity, leading to a reassessment of the self and life goals, and that the symptoms of illness lead to physical and emotional changes that affect the sense of self. Responses from others may also 
influence a person's self-esteem. People with a long-term illness must reinterpret their future in light of possible limitations. The psychologic project to be resolved in this new life stage revolves around adapting to and coming to terms with the new self. De Ridder et $\mathrm{al}^{30}$ further discuss the physiologic, emotional, behavioral, and cognitive aspects of psychologic adjustment to chronic illness. They conclude that patients should remain as active as is reasonably possible, acknowledge and express their emotions in a way that allows them to take control of their lives, engage in self-management, and try to focus on potential positive outcomes of their illness. Patients who can use these strategies have the best chance of successfully adjusting to the challenges posed by a chronic illness.

Scherman and Lowhagen ${ }^{31}$ conducted a longitudinal qualitative study describing asthma/allergy patients' experiences of medication. Three categories were identified, ie, "access to medicine is important to relieve discomfort and to avoid fear"; "medicine damages your body and your identity without curing the illness" (because "you can become immune or addicted", "the ability of your body to heal itself is weakened", "your body's own signals are camouflaged", and "you become stigmatized"), and "production and distribution of medicine is a profit-seeking commercial undertaking which is not primarily aimed at curing the patient". Medication experiences were stable over time. It was concluded that sociologic and biologic survival must be compared in open discussions with the patient's and health professional's different reasons for how they take or prescribe medication, respectively.

Telford et $\mathrm{al}^{32}$ explored the terms of acceptance and denial with the aim of categorizing people's responses to living with chronic illness. They note that the chronically ill may be labeled by others as being in denial of their illness or indeed their identity as chronically ill persons, particularly when they do not adhere to prescribed treatments. According to this study, health care professionals commonly refer to the terms "acceptance" and "denial" when describing a person's response to chronic illness. Health care providers who use this acceptance-denial framework may not be able to listen when people with chronic illness attempt to tell their own unique story of how they have experienced life with illness. Instead, their listening antennae may be focused on fitting aspects of the patient's experience to stages of acceptance or denial. When others use the labels of acceptance and denial, people who are learning to live with a chronic illness may internalize these labels as a reflection of the self. This may be most likely when the person using the label is perceived to be an authority, such as a health care professional. The authors urge health care professionals to challenge the stage model of adjustment as a way of understanding the response to illness and to listen instead to the stories people tell in order to privilege the person's experience as the basis for developing a sensitive response that takes into account the wider social context of people's lives, in addition to the medical aspects.

\section{Information sources and decision-making}

Medical sociologists have argued that it is simplistic to believe that when patients make decisions about their treatment they are blindly led by their physician and that they do not renegotiate the use of drugs according to their own judgment. Non-compliance with medical regimens can be better explained by the rational accumulation of information by the patient from his/her entire network, in addition to information received from medical "experts". ${ }^{33}$ According to the school of symbolic interactionism, people's reactions to drugs are mediated by the beliefs, expectations, and knowledge they have acquired through interaction with other people and by previous experiences. ${ }^{34,35}$ Drug-taking activities are structured by a social context in which the drug user is told by drug-using peers what physical or psychologic sensations to expect and how to recognize their effects. ${ }^{36}$ In the case of prescription drugs, it is the prescribing doctor, not peers, who relays drug information to the user and acts as an authority figure regarding the effects (or side effects) of the drugs. However, in our society, people tend to receive information about what they might do about their health from many different sources, including family members, friends, and the media. They take this information into account in assessing their need for medical treatment. In this sense, people's social relationships have a bearing on their healthrelated behavior. ${ }^{35}$

The use of the Internet for finding health and disease information is widely acknowledged. ${ }^{37}$ Patient empowerment has also led to greater skepticism about advice from doctors, and in some cases has undermined the dominant medical paradigm and supported CAM. ${ }^{38}$

\section{Case study}

This article is based on a small-scale qualitative study of 26 asthmatics selected through Astma Fonds, ${ }^{39}$ a platform for Dutch asthma patients. Written consent was obtained from this group, and the results of the study were forwarded to the interview and focus group participants. Consent to publish 
the results was obtained from all participants. Semistructured interviews were conducted with 19 subjects who had used conventional medicine at least once prior to selecting CAM or who continued to use CAM simultaneously with conventional medication. The sample included 12 women and seven men between the ages of 29 and 65 years, who were selected on the basis that they had been officially diagnosed with asthma by a physician, were noncompliant with the drug regimen prescribed by their physician or lung specialist, and used CAM, such as TCM, Ayurvedic medicine, herbal therapy, acupuncture, yoga, homeopathy, chiropractic medicine, and/ or massage therapy. Of the total sample, 15 patients had used prescribed medication prior to their switch to CAM, and eight still occasionally resorted to it (in combination with CAM). Four subjects, having been diagnosed with asthma by their physician, never complied with the prescribed medical regimen. Of these, three consulted an alternative practitioner, and one did not consult any practitioner, relying instead on "selfmedication" (a combination of alternative treatments) since the time of diagnosis. The most common type of medication used was TCM, used by 11 subjects, followed by homeopathic medication, used by four subjects, and Ayurvedic medicine, used by two subjects (both of whom combined it with yoga and other therapies). The two remaining subjects used a combination of methods, consisting of herbal and chiropractic medicine, as well as massage therapy. TCM was reported to be the most successful (nine of 11 TCM users were satisfied with the results), followed by homeopathic medicine (two of four subjects were fully satisfied).

Semistructured individual interviews were recorded and transcribed between June 2009 and January 2010. In 17 cases the interviews were recorded once, while two interviewees volunteered for a second session because they felt that the initial interviews needed to be supplemented with additional information. Initial interview questions were directed at patients' experiences related to their selection of CAM, based on four main forms of encounters, ie, the patient's own illness and identity as an asthma patient, with medical practitioners (family physician, lung specialist), available information on disease and medical treatments from sources including online and printed media, and information and advice from patients' social groups (patient organizations, family, peers, etc.). Additionally, all 19 participants were asked to supply additional information, such as prescription details and printouts of online sources related to asthma medication. In addition to the interviews, a focus group meeting was held with the seven subjects who had never used conventional medication. Focus group themes centered on the four encounters described above, with an additional theme focusing on CAM. The focus on CAM was broken down into specific questions addressed to the group by the moderator, ie, what type of CAM treatment the subjects use, what encounter (with medical practitioners, a social group, online sources, etc) or combination of encounters was most important in determining this choice (if any), and experiences with the use of CAM, including the patient's own experiences and anecdotal evidence. Thematic analysis was used for evaluating the results of this session.

Data from the semistructured interviews and the focus group sessions were transcribed and the qualitative data analysis program MAXQDA (http://www.maxqda. com/maxqda-eng/index.htm) was used for data analysis.

\section{Perception of illness and patient identity}

Interview questions related to the subjects' experience of asthma and their own identity included those associated with the asthma symptoms experienced, as well as patient acceptance or denial of their condition. It appeared that most subjects in the sample did not deny their identity as asthmatics nor underplay the severity of their symptoms. While one of the subjects described her symptoms as "acute" rather than chronic, she noted that the acute periods "sometimes do come back," although she could not detect any specific patterns, such as environmental stimuli or triggers. The majority of the subjects in the sample $(n=15)$ acknowledged that they "had asthma" and "were asthmatic", while four subjects stated only that they "had asthma" and preferred not to "stick the sickness label" on themselves, as one of the subjects described it. Most of the subjects $(n=17)$ agreed with the doctor's diagnosis of asthma, although two subjects referred to the diagnosis made by the alternative practitioner (Chinese or Ayurvedic practitioner), as a "disease of the lungs" or an "imbalance". These two subjects however, had combined both the Western practitioner's diagnosis and that of the alternative practitioner.

Among those interviewed, seven subjects experienced their asthma as something they should not discuss in public or at work due to the possible stigma of "being sick" or, as one patient put it, a "sign that you're growing old". However, all subjects except for two felt that it is "something that has to be dealt with" and "cannot be left untreated". One patient remarked, self-deprecatingly, "Well, I just hope it will go away".

During the focus group session, the theme of negative stereotyping was expanded, with four of seven participants 
referring to "stigma", "being pigeon-holed", or "exclusion" as some of the aspects of their experience of being asthmatic. One example cited was the law banning smoking in public spaces. Dutch legislation imposed a smoking ban in all public places beginning in the summer of 2008 which has subsequently loosened under public pressure. Small cafes in particular refused to comply with the smoking ban in 2008, a trend that spread to larger cafes and to bars in 2009. Subjects reported that, despite their protests to café owners, bar personnel, and smokers themselves, their complaints were largely dismissed. Describing such encounters, two subjects felt relegated to the category of "a sick person" who "should not be going (to cafes) in the first place". Both indicated that cigarette smoke caused them to experience asthma symptoms and felt that their "sick" label was deserved, but described the behavior of bar personnel as "arrogant" and "inconsiderate". All seven participants referred to themselves as "asthmatic" but did not necessarily see asthma as a chronic or incurable condition. In addition to seeing themselves as asthmatic, three referred to themselves as suffering from an "imbalance", referring to a holistic identification of illness common to CAM.

\section{Encounters with medical practitioners}

Experiences with medical practitioners varied greatly, from being confronted with a "very knowledgeable and attentive physician" to a "self-assured, know-little, so-called specialist". In the latter negative case, three of six subjects sought a second opinion, and two evaluated the second practitioner as being better than the first. An overwhelming feeling among those who had consulted physicians on multiple occasions ( $n=11$ ) was that the physician was "very convincing" and "quite insistent" about the use of medicines containing budesonide (a corticosteroid) and/or formoterol (a longacting $\beta_{2}$-agonist).

Alternatives were not discussed, except when subjects initiated the discussion themselves. In one case, the doctor's reaction to a patient's question about alternatives was "But why?" When the patient responded that she was afraid of the long-term effects of Symbicort ${ }^{\circledR}$, the doctor asked "What effects?" The exchange went on, with the patient insisting that she had read studies indicating that there are apparent risks, and the doctor insisting that "all medicines have risks" and that she was not aware of any risks with long-term use of Symbicort. When the patient produced the prescription drug warnings included with her medicine, the doctor suggested alternatives (all of which contained budesonide and formoterol). When asked about alternative medicine, such as Ayurveda, the doctor, according to the patient, shrugged and replied that "These are not real alternatives". The patient insisted on getting a second opinion and was referred to a lung specialist, who agreed with the family physician that the only adequate treatment was medication containing budesonide and formoterol. At this stage, the patient acknowledged her desire to seek an opinion from an alternative practitioner. The doctor asked the patient not to stop taking the prescribed medication while using alternatives, with the patient retorting that the effects of alternative medicine would not be known unless she stopped using conventional medication. The doctor then suggested that use of complementary medicine (rather than the exclusive use of alternative medication) would be a good compromise. The patient reflected that it would only be a good compromise for the doctor herself, since by allowing the use of alternative medicine in a "complementary" way, the doctor made sure that the patient stayed on "safe and proven" allopathic medicine. According to the patient, the doctor tried to "trick her", refused to take her concerns seriously, and "completely discounted the possibility of the effectiveness of alternative medication when taken on its own".

Another patient related a story about an encounter with her doctor, who was aware of the long-term risks of the medication but considered them to be "the lesser of two evils", implying that if the asthma was left untreated, the patient will have a greater risk of death in the long term. The patient replied that she did not intend to leave her asthma untreated; rather, she was looking for alternatives to what she considers to be a "heavy medicine". The patient then mentioned her age of 29 years and that if she took her medication continuously as prescribed, by the age of 50 she "might be dead". To this, the doctor, according to the patient, became "really upset" and talked to her "like she was a small, stubborn girl", speaking very slowly and distinctly, indicating that the patient's concerns were "irrational". The patient went for a second and third opinion and while she encountered "more open-minded specialists", she felt that her fears were not taken seriously.

In another case, a male patient with severe long-standing asthma (untreated for at least five years) revealed that his encounter with a doctor resulted in him "walking out of the doctor's office" because the doctor "blamed (him) for not coming in earlier", for "continuing to smoke while knowing it is bad", and for "not taking her (the doctor's) opinion seriously". The patient felt insulted by the doctor's "arrogant attitude" and "complete lack of understanding". 
However, the second doctor consulted by the same patient was "well-informed" and "respectful" and suggested treatment in combination with lifestyle changes (quitting smoking). While the patient followed the recommendation and managed to quit smoking, he became concerned about the side effects of the prescribed medication and contacted the same doctor again with questions about alternatives. The doctor actually suggested that the patient should consider alternative medicine, while warning him that "to the extent of his knowledge", commonly prescribed medications "work best". The doctor suggested, however, that he did not recommend alternative medications himself, and that if the patient chose alternative methods, he "will need to keep himself very well informed" and would be choosing CAM treatment "at his own risk".

While the first two subjects felt that they were perceived as "ill-informed", "stubborn", and "irrational" by the doctors they consulted, most subjects in this sample had an experience similar to the last patient described. The majority of doctors encountered by the subjects in the sample insisted that prescribed medication "works best" or is the "most proven" method of controlling asthma. Doctors were not always adamant about discouraging patients to seek information about alternatives, but expected that use of alternative treatment would not lead to positive results. Doctors' opinions about CAM, according to subjects, varied from viewing it as a "quack trade" to being "a viable alternative, perhaps, although not well studied ... yet".

The focus group session described similar experiences to those in the group of exclusive CAM users, with the significant difference being that their opinion of the medical practitioners' expertise was very low. One patient in the group felt that "none of the doctors" she has consulted had any respect for her concerns. This was echoed by two other women in the group, who considered that the doctors might have attributed their concerns to "female whims" or "hysteria". This opinion was offset by the only male in the group, who said that his experience with doctors was just as humiliating and had nothing to do with gender.

\section{Printed and online information}

All of the subjects in the interview sample who have tried prescribed medication $(n=15)$ indicated that they read the instructions for use enclosed in the package. Nine subjects also consulted online information about the drug prescribed for them; a further five read articles related to their medication. Most subjects $(n=17)$ consulted the Internet to find out about the risks and benefits of their prescribed medication. Of these, 10 consulted Dutch language sources only. Five consulted printed sources, such as books and articles from a library. The most common research subject was the possible side effects and risks of the prescribed medication. Other subjects included correct use, other patients' experiences, chemical composition and properties of the medicine, and research on the use of the medicine. One patient described his experience with online sources:

"First, I was overwhelmed by the amount of data (on the Internet). Then, I was even more overwhelmed by the amount of conflicting data. And the advice people give (online) ... some say 'use it', others say 'no, never, it's dangerous!' ... from what I could gather, it was clear that there is no agreed-upon opinion ..."

This quote is quite typical of the responses from those interviewed, with most of them indicating that they encountered confusing data, some having "problems with understanding the (medical) jargon" and having trouble deciding which sources are "most reliable". However, most of them indicated that on the basis of the information they found, they were able to make "an informed choice".

\section{Supplementary information from patients}

The following information was provided by the subjects themselves. Ten indicated that the controversy around the safety of medicines containing budesonide and/or formoterol has been "particularly disturbing". As one of the subjects eloquently put it, referring to the others participating in the study, "but then of course, we're all skeptical asthmatics". Another said "Well, that's what you get with selection bias". The same subject supplied a collection of articles indicating that the use of preventive drugs for asthma is associated with potentially severe side effects. Most of the articles referred to studies of preventive medications containing budesonide and formoterol. One of the articles provided by the same asthmatic was by Nieto et $\mathrm{al}^{25}$ who argue that independently funded studies of inhaled corticosteroids are up to four times more likely to find adverse effects than studies paid for by drug companies.

Another set of articles provided by the same subject addressed medical statistics. Salpeter et al asserted that clinical trials demonstrate that the long-acting $\beta_{2}$-agonists cause a statistically significant number of deaths when compared with patients taking placebo. ${ }^{40}$ This research, published in 2006 , found that long-acting $\beta_{2}$-agonists increased the risk for asthma hospitalizations and asthma deaths by two- to four-fold compared with placebo. ${ }^{40,41}$ 
Online sources available to the subjects, who supplied them to the researchers, included information about warnings on the medication label for Symbicort, the drug most subjects in this study were prescribed $(n=9)$, indicating a risk of asthma-related death (see case study at the end of this article). One subject brought in the prescribing information with underlined passages from the warnings:

"A 28-week, placebo-controlled US study comparing the safety of salmeterol with placebo, each added to usual asthma therapy, showed an increase in asthma-related deaths in patients receiving salmeterol $(13 / 13,176$ in patients treated with salmeterol vs $3 / 13,179$ in patients treated with placebo; relative risk $4.37,95 \%$ confidence interval $1.25,15.34)$. The increased risk of asthma-related death may represent a class effect of the long-acting beta ${ }_{2}$-adrenergic agonists, including formoterol. No study adequate to determine whether the rate of asthma-related death is increased with Symbicort has been conducted".

A patient who normally resided in the US supplied the US prescribing information enclosed with Advair Discus ${ }^{\circledR}$ containing fluticasone (a corticosteroid) and salmeterol (a long-acting $\beta_{2}$-agonist). Data from a large placebocontrolled US study that compared the safety of salmeterol or placebo added to usual asthma therapy showed an increase in asthma-related deaths in patients receiving salmetorol (13 deaths in 13,176 patients treated for 28 weeks on salmeterol versus three deaths in 13,179 patients on placebo).

Another patient supplied a link to a website (http://www. rxlist.com/symbicort-drug.htm) with information on a recent meta-analysis of the roles of long-acting $\beta_{2}$-agonists, indicating that they may pose a danger to asthma patients. Longacting $\beta_{2}$-agonists may increase the risk of asthma-related death. Data from a large placebo-controlled US study that compared the safety of salmeterol or placebo added to usual asthma therapy showed an increase in asthma-related deaths in patients receiving salmeterol. This finding with salmeterol may apply to formoterol $\left(\beta_{2}\right.$-agonist), one of the active ingredients in Symbicort. Clinically significant cardiovascular effects and fatalities have been reported in association with excessive use of inhaled sympathomimetic drugs.

All 19 subjects researched CAM through a combination of printed and online sources, complemented by online patient forums (such as Astma Fonds and alternative medicine forums). The opinion of an overwhelming number $(n=17)$ of the subjects was that alternative medicines seemed "less threatening", and that there were "no apparent risks". While the data were also conflicting and patchy, most subjects felt that "once you've found the right source" (ie, a source they could trust) it was "easy to navigate" and "find information". Criteria for choosing "the right source" differed greatly from patient to patient. Most sources viewed as reliable originated from established or well-known medical institutions, or included research done by "specialists" (by which some subjects meant health practitioners, while others meant medical researchers). Evidence from others, especially if gleaned from online forums (five subjects consulted international rather than Dutch forums) was also rated high on the reliability scale.

\section{Encounters with subjects' social groups}

In addition to information obtained from practitioners or discovered by subjects themselves in printed and/or online sources, social networking served as an information source, albeit to a more limited extent. In most cases, subjects consulted close relatives and friends rather than extended family members or colleagues. Eight subjects reported receiving advice from other asthmatics, notably through Astma Fonds. Fellow asthmatics constituted a group whose "opinions were valued" or whose advice was sought as a complement to other sources of information. Opinions and advice given by family, friends, and fellow asthmatics differed greatly with regard to prescribed medication, patient decisions about compliance, and CAM.

The most important source of information about asthma medication for the focus group participants was friends, family members, or fellow asthmatics whose use of CAM had been beneficial. Despite the fact that all seven participants in the sample were discouraged from using CAM by their doctor, there was abundant anecdotal evidence of success in curative terms, rather than preventive or symptom-relieving treatment. During the discussion, participants stated that while conventional asthma medications were geared towards relieving the symptoms of asthma, preventing their exacerbation, and preventing asthma attacks, they were not presented as "curing" asthma. All seven discussion participants stated their belief that medical practitioners (one patient included the "pharmaceutical industry" and "insurance companies") insist that asthma is "chronic" and "incurable" by definition. The subjects reported the experiences of other asthma sufferers (friends, family members, or members of online forums), as well as the views of CAM practitioners (including TCM or Ayurveda) who maintain that asthma is not necessarily "incurable". All seven participants mentioned that they "knew people" in their immediate social circle who were "cured of asthma" or at least no longer had 
asthma symptoms. When the moderator asked about how long these contacts had been symptom-free, and whether the symptoms had disappeared altogether, the responses were inconclusive.

Another important aspect of the positive experiences reported by the group using CAM was the belief that "CAM has no serious side effects" and that it is "safe to use". When the moderator asked subjects to elaborate on the evidence for this belief, the participants stated that "people they knew" had never reported any negative effects from TCM, Ayurvedic, or homeopathic treatments. The only reported side effect of the use of certain herbs in TCM treatment was "excessive urination" which participants laughed at and did not find threatening ("Not in comparison with heart attacks", one of the participants said).

\section{Results and discussion}

The driving question behind this study was why some asthma patients decided not to comply with their prescribed medication regimens and choose to use CAM instead. We have explored whether the patients' rights movement has led to a greater awareness of the benefits of alternative medicine. In the present study, we discovered that, on the whole, subjects were well informed about the risks and benefits of both prescription and alternative medicines (see Table 1). While the risks of commonly prescribed medications (as revealed in the results of clinical trials) were particularly noted by the subjects, the benefits of CAM (not tested in clinical trials but based on anecdotal evidence) were emphasized. We argue that noncompliance with medical regimens by some asthmatics can be explained by the rationality of their choice, which is based on evidence from clinical trials of commonly prescribed asthma medications, as well as on partial and anecdotal evidence of the benefits of CAM. We also argue that it is the patients themselves who, by invoking the evidence-based dominant medical paradigm, choose to address the conflict between conventional Western medicine and other modalities. Concerns about the side effects and long-term risks of conventional asthma medications motivated the patients to choose alternative treatment. We can conclude that noncompliance with prescribed medical regimens is less a matter of patient denial or acceptance of

Table I Reasons given by patients for choosing CAM options to manage their asthma

\begin{tabular}{|c|c|c|c|}
\hline Topic & Interviews (n = 19) & (Focus group $n=7$ ) & Discussion \\
\hline $\begin{array}{l}\text { Perception of illness } \\
\text { and own identity }\end{array}$ & $\begin{array}{l}\text { Most patients did not deny their } \\
\text { identity as asthma sufferers nor } \\
\text { underplay the severity of their } \\
\text { symptoms. Stigma relating to the } \\
\text { illness was resented. }\end{array}$ & $\begin{array}{l}\text { All participants referred to } \\
\text { themselves as "asthmatic" but } \\
\text { did not necessarily see asthma } \\
\text { as a chronic or incurable } \\
\text { condition. Some referred to an } \\
\text { "imbalance" in the system. }\end{array}$ & $\begin{array}{l}\text { Most patients in the } \\
\text { study ( } n=24) \text { referred to } \\
\text { themselves as asthma sufferers, } \\
\text { most experienced the "stigma" } \\
\text { of being seen as "sick". Asthma } \\
\text { was not necessarily seen as } \\
\text { incurable. }\end{array}$ \\
\hline $\begin{array}{l}\text { Encounters with medical } \\
\text { practitioners }\end{array}$ & $\begin{array}{l}\text { Mixed experiences, in more than } \\
\text { half of the cases patients } \\
\text { requested a second opinion. }\end{array}$ & $\begin{array}{l}\text { Mostly negative experiences, } \\
\text { especially in relation to their } \\
\text { noncompliance with a } \\
\text { medication regime and use } \\
\text { of CAM. }\end{array}$ & $\begin{array}{l}\text { Focus group patients choosing } \\
\text { to use CAM exclusively found } \\
\text { little support from their } \\
\text { physicians, while complementary } \\
\text { users had more positive } \\
\text { experiences. }\end{array}$ \\
\hline $\begin{array}{l}\text { Encounter with print } \\
\text { and online information } \\
\text { on asthma and medical } \\
\text { treatments }\end{array}$ & $\begin{array}{l}\text { The majority of patients } \\
\text { demonstrated an awareness of the } \\
\text { negative results of clinical trials of } \\
\text { conventional medications; they } \\
\text { were most concerned about } \\
\text { controversies and potential risks. }\end{array}$ & $\begin{array}{l}\text { All participants were aware of } \\
\text { potential negative effects of } \\
\text { conventional medicine. All were } \\
\text { convinced that conventional } \\
\text { medicine offers symptom relief } \\
\text { only and that CAM is less } \\
\text { dangerous and has the potential } \\
\text { to "cure" asthma. }\end{array}$ & $\begin{array}{l}\text { Most patients discovered } \\
\text { significant risks in the long-term } \\
\text { use of conventional medications. } \\
\text { Alternative medicines were } \\
\text { referred to as "less } \\
\text { threatening", and containing "no } \\
\text { apparent risks" in comparison } \\
\text { to conventional medicine. }\end{array}$ \\
\hline $\begin{array}{l}\text { Encounter with } \\
\text { patients' social groups } \\
\text { (patient organizations, } \\
\text { family, peers, etc) }\end{array}$ & $\begin{array}{l}\text { Mixed experiences. In most cases, } \\
\text { close relatives and friends were } \\
\text { consulted about medication } \\
\text { choices rather than extended } \\
\text { family or colleagues. }\end{array}$ & $\begin{array}{l}\text { All participants consulted other } \\
\text { patients who had experience } \\
\text { with CAM. The anecdotal } \\
\text { evidence of CAM's success in } \\
\text { treating asthma was of } \\
\text { paramount importance in the } \\
\text { decision not to use } \\
\text { conventional medicine. }\end{array}$ & $\begin{array}{l}\text { While the subjects interviewed } \\
\text { based their decision mostly on } \\
\text { limited exchanges with their } \\
\text { close family and friends, focus } \\
\text { group subjects relied mostly on } \\
\text { information conveyed by other } \\
\text { asthmatics using CAM. }\end{array}$ \\
\hline
\end{tabular}

Abbreviation: CAM, complementary and alternative medicine. 
a diagnosis of asthma and its severity, but more a matter of rational choice informed by an awareness of evidence-based results. We refer here particularly to the patients' awareness of the rather controversial results of clinical trials of commonly used asthma medicines, particularly those containing budesonide and formoterol.

These findings, if supported by more extensive study, may lead to some revision in medical decision-making. Because medical decision-making emphasizes the importance of evidence-based knowledge or judgment, a patient's informed perspective may need to be considered as part of the overall evidence and therefore, as part of the basis for joint decision-making. We have, however, noted that integrating "alternative" patient perspectives may be difficult due to the dominance of "evidence-based" prescribing, the delivery of which is largely funded by governments (and by the pharmaceutical industry and insurance companies), and supported by a system of education in which alternatives are viewed as irrational, not evidence-based, useless, and even potentially dangerous. This can create a negative cycle in which CAM is not tested according to the standards of EBM because there is not enough evidence available to prove that some types of CAM can be indeed safe and effective in the treatment of asthma. Until systematic, large-scale studies of the safety and efficacy of CAM are conducted, asthma patients choosing CAM will continue to resort to anecdotal evidence.

It is remarkable that, at present, hardly any clinical trials of CAM have been conducted. The results of this study demonstrate that a thorough investigation of the reasons behind Western medicine's reluctance to engage in clinical trials of CAM is desired by patients. When these reasons (and particularly priorities in government spending) are outlined, clinical trials of CAM should lead to greater patient confidence and compliance with prescribed medical treatments for asthma. However, it should be acknowledged that this paper reports a small case study and that the results cannot be generalized to the whole population of CAM users. This study, however, is a plea for further research into the issue of patients' views of commonly prescribed asthma medication by professionals involved in the treatment of asthma, as well as for the provision of funding by relevant government, insurance, and pharmaceutical agencies.

\section{Disclosure}

The authors report no conflict of interest in this work.

\section{References}

1. Elstein AS. On the origins and development of evidence-based medicine and medical decision making. Inflammation Research. 2004;53 Suppl 2:S184-S189.

2. Evidence-Based Medicine Working Group. Evidence-based medicine. A new approach to teaching the practice of medicine. JAMA. 1992;268(17):2420-2425.

3. Ezzo J, Bausell B, Moerman DE, Berman B, Hadhazy V. Reviewing the reviews. How strong is the evidence? How clear are the conclusions? Int J Technol Assess Health Care. 2001;17(4):457-466.

4. Timmermans S, Mauck A. The promises and pitfalls of evidence-based medicine. Health Aff. 2005;24(1):18-28.

5. Sackett DL, Rosenberg WM, Gray JA, et al. Evidence-based medicine: What it is and what it isn't. BMJ. 1996;(7023);312:71-72.

6. World Health Organization. Global surveillance, prevention and control of chronic respiratory diseases: A comprehensive approach. Geneva: World Health Orgaization; 2007. Available at: http://www. who.int/gard/publications/GARD_Manual/en/index.html. Accessed Apr 25, 2010.

7. Braman SS. The global burden of asthma. Chest. 2006;130 1 Suppl:4S-12S.

8. Williams SG, Schmidt DK, Redd SC, et al. Key clinical activities for quality asthma care: Recommendations of the National Asthma Education and Prevention Program. MMWR. 2003;52(RR-6):1-8.

9. Lagerløv P, Veninga CC, Muskova M, et al. Asthma management in five European countries: Doctors' knowledge, attitudes, and prescribing behaviour. Eur Respir J. 2000;15(1):25-29.

10. Pearson MG. How can the implementation of guidelines be improved? Chest. 2000;1172 Suppl:38S-41S.

11. Markham AW, Wilkinson JM. Complementary and alternative medicines (CAM) in the management of asthma: An examination of the evidence. J Asthma. 2004;41(2):131-139.

12. The National Center for Complementary and Alternative Medicine (NCCAM). Available at: http://nccam.nih.gov/research/clinicaltrials/ factsheet/. Accessed Apr 25, 2010.

13. Freidin B, Timmermans S. Complementary and alternative medicine for children's asthma: Satisfaction, care provider responsiveness, and networks of care. Qual Health Res. 2008;18(1):43-55.

14. Mazur L, De Ybarrondo L, Miller J, Colasurdo G. Use of alternative and complementary therapies for pediatric asthma. Tex Med. 2001;97(6):64-68.

15. Cuzzolin L, Zaffani S, Murgia V, et al. Patterns and perceptions of complementary/alternative medicine among paediatricians and patients' mothers: A review of the literature. Eur J Pediatr. 2003; 162:820-827.

16. Ko J, Lee JI, Munoz-Furlong A, Li XM, Sicherer SH. Use of complementary and alternative medicine by food-allergic patients. Ann Allergy Asthma Immunol. 2006;97(3):365-369.

17. Kealoha MK. What's new in alternative therapies for asthmatic children? J Community Health Nurs. 2009;26(4):198-205.

18. Li XM, Brown L. Efficacy and mechanisms of action of traditional Chinese medicines for treating asthma and allergy. J Allergy Clin Immunol. 2009;123(2):297-306.

19. Stockert K, Schneider B, Porenta G, Rath R, Nissel H, Eichler I. Laser acupuncture and probiotics in school age children with asthma: A randomized, placebo-controlled pilot study of therapy guided by principles of Traditional Chinese Medicine. Pediatr Allergy Immunol. 2007;18:160-166.

20. Wei L, Gong C. Expert advice - Treatment of asthma in traditional Chinese Medicine (TCM). Available at: http://www.tcmpage.com/ hpasthma.html. Accessed on Apr 25, 2010.

21. Arnold E, Clark CE, Lasserson TJ, Wu T. Herbal interventions for chronic asthma in adults and children. Cochrane Database Syst Rev. 2008;(1):CD005989. 
22. Bielory L, Russin J, Zuckerman G. Clinical efficacy, mechanisms of action, and adverse effects of complementary and alternative medicine therapies for asthma. Allergy and Asthma Proceedings. 2004;25(5):283-291.

23. Mainardi T, Kapoor S, Bielory L. Complementary and alternative medicine: Herbs, phytochemicals and vitamins and their immunologic effects. J Allergy Clin Immunol. 2009;123(2):283-294.

24. Verkerk R. Can the failing western medical paradigm be shifted using the principle of sustainability? ACNEM J. 2009;28(3). Available at: http://www.anhcampaign.org/files/ACNEM_Journal_Sept2009_RV_ article_pdf.pdf. Accessed on Apr 25, 2010.

25. Nieto A, Mazon A, Pamies R, et al. Adverse effects of inhaled corticosteroids in funded and nonfunded studies. Arch Intern Med. 2007;167(19):2047-2053.

26. Evans L, Spelman M. The problem of non-compliance with drug therapy. Drugs. 1983;25(1):63-76.

27. Mühlhauser I, Lenz M. Does patient knowledge improve treatment outcome? Z Evid Fortbild Qual Gesundhwes. 2008;102(4):223-230. German.

28. Adams S, Pill R, Jones A. Medication, chronic illness and identity: The perspective of people with asthma. Soc Sci Med. 1997;45(2):189-201.

29. Beatty JE, Joffe R. An overlooked dimension of diversity: The career effects of chronic illness. Organizational Dynamics. 2006;35(2):182-195.

30. De Ridder, Geenen R, Kuijer R, van Middendorp H. javascript:AL_get (this, 'jour', 'Lancet'.);Psychological adjustment to chronic disease. Lancet. 2008;372(9634):246-255.

31. Scherman MS, Lowhagen O. Reasons for non-compliance: Experiences of medication from persons with asthma/allergy. Patient Educ Couns. 2004;54(1):3-9.
32. Telford K, Kralik D, Koch T. Acceptance and denial: Implications for people adapting to chronic illness. Literature review. J Adv Nurs. 2006;55(4):457-464.

33. Stimson GV. Obeying doctor's orders. A view from the other side. Soc Sci Med. 1974;8(2):97-104.

34. Becker HS. Consciousness, power and drug effects. Society. 1973;10:67-76.

35. Haafkens JA. Rituals of silence. Long-term tranquilizer use by women in the Netherlands. A Social Case Study. Amsterdam: Het Spinhuis; 1997.

36. Zinberg NE. Drug, set, and setting. The basis for controlled intoxicant use. New Haven: Yale University Press; 1984.

37. Larner AJ. Cluster headache: Self diagnosis by internet. A research letter. Headache Care. 2006;3(2-3):53-55.

38. Broeks C. Hogeropgeleide vrouw zoekt alternatieve arts. [Well-educated woman seeks an alternative doctor] Trouw. 2009 May. Available at: http://www.trouw.nl/achtergrond/deverdieping/article2771983.ece/. Accessed Apr 25, 2010.

39. Astma Fonds. Available at: http://www.astmafonds.nl; http://www longforum.nl/. Accessed Mar 29, 2010.

40. Salpeter S, Buckley N, Ormiston T, Salpeter E. Meta-analysis: Effect of long-acting beta-agonists on severe asthma exacerbations and asthmarelated deaths. Ann Intern Med. 2006;144(12): 904-912.

41. Ramanujan K. Common asthma inhalers cause up to 80 percent of asthma-related deaths, Cornell and Stanford researchers assert. Cornell News Service. June 9, 2006. Available at: http://www.news.cornell.edu/ stories/June06/AsthmaDeaths.kr.html. Accessed Apr 25, 2010.
Patient Preference and Adherence

\section{Publish your work in this journal}

Patient Preference and Adherence is an international, peer-reviewed, open access journal that focusing on the growing importance of patient preference and adherence throughout the therapeutic continuum. Patient satisfaction, acceptability, quality of life, compliance, persistence and their role in developing new therapeutic modalities and compounds to

\section{Dovepress}

optimize clinical outcomes for existing disease states are major areas of interest. This journal has been accepted for indexing on PubMed Central. The manuscript management system is completely online and includes a very quick and fair peer-review system. Visit http://www.dovepress.com/ testimonials.php to read real quotes from published authors. 